\title{
Analisis Kandungan Mineral Pasir Pantai Bajul Mati Kabupaten Malang Menggunakan XRF dan XRD
}

\section{Sumari*, Yana Fajar Prakasa, Muhammad Roy Asrori, Dinar Rachmadika Baharintasari}

Universitas Negeri Malang, Malang, 65145, Indonesia

\begin{tabular}{l} 
IN F O A R T I K E L \\
\hline Diterima 11 Juni 2020 \\
Disetujui 20 Oktober 2020 \\
\\
\hline Key word: \\
Bajul Mati Beach Sand \\
XRF \\
XRD \\
\hline Kata kunci: \\
Pasir Pantai Bajul Mati \\
XRF \\
XRD
\end{tabular}

*e-mail: sumari.fmipa@um.ac.id

\begin{abstract}
A B S T R A C T
Mineral exploration in Indonesia has not been evenly distributed, so a study with title analysis of the sand mineral content of Bajul Mati Malang Regency was carried out using XRF and XRD. The aims of this study to determine the percentage of mineral that containing in the sand of Bajul Mati beach in Malang Regency. The instruments used XRF and XRD where the samples were placed in a sample holder and irradiated with $X$-rays then. The result of analysis of mineral content and metal oxide in Bajul Mati beach sand showed that the beach sand of Bajul Mati has the big potential to be used as a base for making nanomaterials. The results of analysis of XRF showed that the content of $\mathrm{SiO}_{2}$ was $46.7 \%$ and the results of analysis of XRD showed that the SiO2 mineral has the quartz phased. Bajul Mati beach sand has the potential to be a source of mineral material
\end{abstract}

\begin{abstract}
A BSTRAK
Eksplorasi mineral di Indonesia belum merata, sehingga penelitian dengan judul analisis kandungan mineral pasir pantai Bajul Mati Kabupaten Malang menggunakan XRF dan XRD telah dilaksanakan. Tujuan penelitian ini adalah mengetahui persentase mineral yang terkandung pada pasir pantai Bajul Mati Kabupaten Malang. Instrumen yang dipergunakan adalah XRF dan XRD dengan sampel diposisikan dalam sample holder, lalu diradiasi menggunakan sinar X. Hasil analisis mineral dan oksida logam yang terkandung pada pasir pantai Bajul Mati menunjukkan bahwa pasir pantai Bajul Mati mempunyai potensi besar sebagai bahan dasar pembuatan nanomaterial. Hasil analisis XRF menunjukkan kandungan $\mathrm{SiO}_{2}$ sebesar 46,7\%, sedangkan hasil analisis XRD menunjukkan mineral $\mathrm{SiO}_{2}$ berfase quartz. Pasir Pantai Bajul Mati berpotensi sebagai sumber bahan mineral.
\end{abstract}

\section{Pendahuluan}

Potensi sumber daya laut Indonesia sangat melimpah, dimana potensi tersebut berupa minyak, perikanan, biomassa, dan bahan-bahan mineral [1]. Bahan mineral oksida seperti $\mathrm{ZnO}$, $\mathrm{SiO}_{2}, \mathrm{MgO}, \mathrm{Al}_{2} \mathrm{O}_{3}, \mathrm{TiO}_{2}$ berpotensi untuk nanoteknologi sehingga diperlukan usaha untuk memaksimalkan penggunaan bahan tersebut. Hasil nanoteknologi dapat berupa nanomaterial, salah satunya adalah sintesis nanosilika dalam jumlah besar untuk dimanfaatkan di bidang elektronika kimia, elektronika, kesehatan, dan bioteknologi [2]. Diketahui, silika banyak terkandung dalam pasir pantai sebanyak $>50 \%$ wt []ㅡ. Dengan demikian, pasir pantai berpotensi sebagai sumber silika dengan eksploitasi yang berpegangan pada undang-undang pemerintah Indonesia.

Indonesia memiliki banyak daerah pesisir pantai, salah satunya adalah Kabupaten Malang bagian selatan. Luas wilayah Kabupaten Malang 3.238,26 km² dengan posisi koordinat antara 7०44',55,11" Lintang Selatan dan 
$8^{\circ} 26^{\prime}, 35,45^{\prime \prime}$ Lintang Selatan dan antara 112¹7',10,90” Bujur Timur dan 122 ${ }^{\circ} 57^{\prime}, 00,00^{\prime \prime}$ Bujur Timur []]. Banyaknya pantai yang terdapat di Malang selatan mengindikasikan bahwa melimpahnya pasir sebagai sumber daya yang sangat berpotensi dimanfaatkan oleh pemerintah setempat. Namun, sampai sekarang pasir tersebut kurang dimanfaatkan oleh masyarakat setempat selain dijadikan objek wisata dikarenakan dinilai tidak memiliki nilai ekonomi yang tinggi. Padahal, apabila masyarakat mengeksplorasi dan mengetahui kandungan mineral yang bermanfaat dalam pasir tersebut, masyarakat dapat memanfaatkan pasir tersebut sebagai material ekonomis, sehingga dapat meningkatkan ekonomi masyarakat pesisir serta pendapatan daerah.

Eksplorasi kandungan mineral telah dilakukan di Indonesia, seperti eksplorasi mineral mangan, pasir besi, emas, dan nikel yang dilakukan di Kabupaten Halmahera Utara [5]. Hal ini menunjukkan sumber daya mineral yang melimpah dan diperlukan strategi eksplorasi yang tepat. Misalnya, eksplorasi pasir besi yang mengandung magnetit $\left(\mathrm{Fe}_{3} \mathrm{O}_{4}\right)$ yang dapat dimanfaatkan sebagai magnetic fluids, katalis, bioteknologi/biomedis, magnetic resonance imaging (MRI), magnetic recording devices [6]. Di negara Malaysia, Filipina, dan Vietnam, pemanfaatan pasir besi dengan kandungan mineral, seperti $\mathrm{Ti}, \mathrm{Zr}$, xenotime, dan monasite dimanfaatkan sebagai bahan pada Rare Earth Magnets. Mineral monasite dan xenotime memiliki kandungan unsur logam tanah jarang seperti Neodinium (Nd) dan Samarium (Sm) [7]. Kebutuhan industri terhadap logam tanah jarang tersebut diperkirakan akan meningkat di masa mendatang karena sifat khas logam tersebut []]. Pasir juga mengandung mineral lain, seperti Ca, $\mathrm{Si}, \mathrm{Mg}$, Ti, dan Fe [9]. Silika $\left(\mathrm{SiO}_{2}\right)$ yang terkandung pada pasir pantai bermanfaat pada bidang nanoteknologi, khususnya pada proses pembuatan nanosilika [10]. Selain itu, silika banyak dimanfaatkan sebagai adsorben, precursor katalis, filter komposit, dan di bidang kelistrikan [111]. Berdasarkan kajian literatur mengenai mineral yang terkandung dalam pasir, maka dilaksanakan penelitian tahap pertama untuk menggali potensi mineral pada pasir pantai Bajul Mati yang terletak di Kabupaten Malang.

Penelitian ini akan mengkaji mineral yang terkandung pada pasir Pantai Bajul Mati. Analisis uji menggunakan X-Ray Diffraction (XRD) dan X-Ray Fluorescence (XRF). Pada penelitian ini juga akan mengkaji tentang struktur silika yang terdapat pasir pantai Bajul Mati.

\section{Bahan dan Metode}

Alat-alat yang dipergunakan meliputi neraca, ayakan 100 mesh, dan mortar. Adapun karakterisasi XRF dan XRD dilakukan uji di Universitas Negeri Malang, tepatnya pada Laboratorium Mineral dan Material Maju, Gedung O4, Fakultas Matematika dan Ilmu Pengetahuan Alam. Bahan-bahan yang dibutuhkan adalah sampel pasir pada pantai Bajul Mati dan akuades.

Preparasi sampel pasir pantai Bajul Mati dilakukan dengan cara: diambil sampel secara representatif (dapat mewakili), dibersihkan kotoran yang terdapat pada sampel, dikeringkan selama 1-2 hari di bawah sinar matahari langsung hingga kering. Sesudah kering, pasir dihaluskan secara fisik menggunakan mortar dan diayak menggunakan ayakan 40-60 mesh.

Analisis XRF bertujuan untuk mengetahui komposisi unsur dan oksida dari mineral yang terkandung dalam pasir pantai Bajul Mati. Pasir pantai Bajul Mati yang telah dikering diletakkan pada sample holder lalu diiradiasi dengan sinar-X. Hasil XRF didapatkan berupa data difraktogram, sehingga selanjutnya dapat diketahui informasi kadar mineral yang terkandung pada sampel pasir pantai Bajul Mati.

Analisis XRD bertujuan untuk mengetahui kristalinitas mineral yang terkandung dalam pasir pantai Bajul Mati. Dalam uji XRD, sampel berupa serbuk halus (powder) diletakkan dalam sample holder. Lalu, permukaan serbuk dimampatkan dan diratakan dengan bantuan alat pressing. Lalu, sample holder diposisikan pada pegangan. Sampel diiradiasi oleh sinar- $X$ dengan sumber radiasi $\mathrm{Cu}$ pada rentang sudut $2 \theta 10^{\circ}$ sampai $90^{\circ}$ hingga terbentuk pola difraksi yang ditunjukkan berupa difraktogram. Selanjutnya, dari data yang diperoleh dapat 
diperoleh informasi dengan memperbandingkan nilai d sampel pada data standar mineral.

\section{Hasil dan Pembahasan}

Analisis mineral yang terkandung pada pasir pantai Bajul Mati antara lain analisis unsur dan senyawa oksida logamnya memanfaatkan instrumen XRF dan kristalinitas mineral memanfaatkan instrumen XRD. Spektroskopi XRF alah sebuah teknik analisis elemen dari suatu sampel dan dapat pula oksida logamnya yang menyusun material dengan terdapatnya interaksi sinar-X dengan material pada sampel pasir. Uji XRF banyak dilakukan dalam analisis mineral dalam pasir maupun batuan. Unsur dapat diketahui secara langsung tanpa pembandingan standar. Hasil analisis unsur dan senyawa oksida logamnya yang terdapat pada pasir pantai Bajul Mati dipaparkan pada Tabel 1.

Tabel 1. Hasil Analisis Unsur dan Oksida Logamnya yang Terkandung pada Pasir Pantai Bajul Mati dengan Bantuan XRF

\begin{tabular}{cccc}
\hline Unsur & $\mathbf{\% W t}$ & Oksida & $\mathbf{\% W t}$ \\
\hline $\mathrm{Ca}$ & 45,3 & $\mathrm{CaO}$ & 36,3 \\
$\mathrm{Si}$ & 31,0 & $\mathrm{SiO}_{2}$ & 46,7 \\
$\mathrm{Fe}$ & 19,0 & $\mathrm{Fe}_{2} \mathrm{O}_{3}$ & 13,5 \\
$\mathrm{Ti}$ & 1,41 & $\mathrm{TiO}_{2}$ & 1,24 \\
$\mathrm{~K}$ & 0,77 & $\mathrm{~K}_{2} \mathrm{O}$ & 0,57 \\
$\mathrm{~V}$ & 0,083 & $\mathrm{~V}_{2} \mathrm{O}_{5}$ & 0,05 \\
$\mathrm{Cr}$ & 0,097 & $\mathrm{Cr}_{2} \mathrm{O}_{3}$ & 0,075 \\
$\mathrm{Mn}$ & 0,43 & $\mathrm{MnO}$ & 0,27 \\
$\mathrm{Cu}$ & 0,1 & $\mathrm{CuO}$ & 0,062 \\
$\mathrm{Sr}$ & 1,8 & $\mathrm{SrO}$ & 1,0 \\
$\mathrm{Eu}$ & 0,1 & $\mathrm{Eu}_{2} \mathrm{O}_{3}$ & 0,1 \\
\hline
\end{tabular}

Sajian data pada Tabel 1 menunjukkan persentase oksida logam tertinggi yang terkandung pada pasir pantai Bajul adalah $\mathrm{SiO}_{2}$ sebesar $46,7 \%$. Selain itu, persentase besi oksida juga cukup tinggi yakni sebesar $13,50 \%$, hal ini dapat diduga dari kenampakan warna pasir pantai Bajul Mati yakni agak kehitaman. Berdasarkan hasil analisis XRF, pasir pantai Bajul Mati sangat berpotensi sebagai bahan dasar pembuatan nanomaterial, khususnya nanosilika. Demikian pula untuk besi oksida yang terdapat pada pasir dapat dimanfaatkan sebagai bahan dasar sintesis nanomaterial feromagnetik.

Spektroskopi XRD adalah suatu cara analisis struktur kristal, fasa, dan mineral pada suatu sampel. Prinsip kerja instrumen XRD ialah penerapan prinsip Bragg yang mengemukakan bahwa perbedaan lintasan berkas difraksi sinar- $X$ harus kelipatan panjang gelombang dengan rumus $n \lambda=d \sin \theta$, dengan $n$ adalah bilangan bulat, sedangkan $\lambda$ adalah panjang gelombang sinar- $X, d$ adalah jarak antar bidang, dan $\theta$ adalah sudut difraksi. Difraktogram yang diperoleh memberikan informasi deretan peaks difraksi dengan intensitas relatif sepanjang nilai $2 \theta$ pada rentang yang ditentukan. Besar intensitas relatif puncak tergantung dari banyaknya atom dalam sampel dan pendistribusinya dalam material. Hasil analisis mineral dengan memanfaatkan instrumen XRD pada intensitas maksimal disajikan dalam Gambar 1.

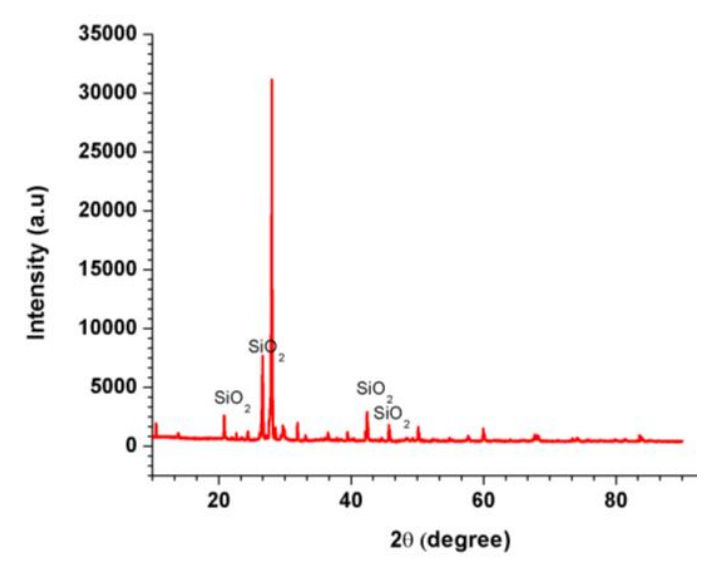

\section{Gambar 1. Hasil Difraktogram Pasir Pantai Bajul Mati Menggunakan XRD}

Analisis kuantitatif sederhana ini dapat dilakukan melalui aplikasi program Match! 3. Pada analisis ini dijelaskankan bahwa hasil analisis kuantitatif yang dipaparkan pada Gambar 1 tidak diperuntukkan sebagai bentuk representasi setiap fase yang terkandung pada sampel pasir Bajul Mati. Perhitungan dilaksakan dengan tujuan untuk mengetahui fase-fase yang dominan dalam sampel pasir, dan kemudian dapat dibandingkan dengan hasil analisis menggunakan instrumen XRF. Hasil perhitungan ditunjukkan dalam Gambar 2. 


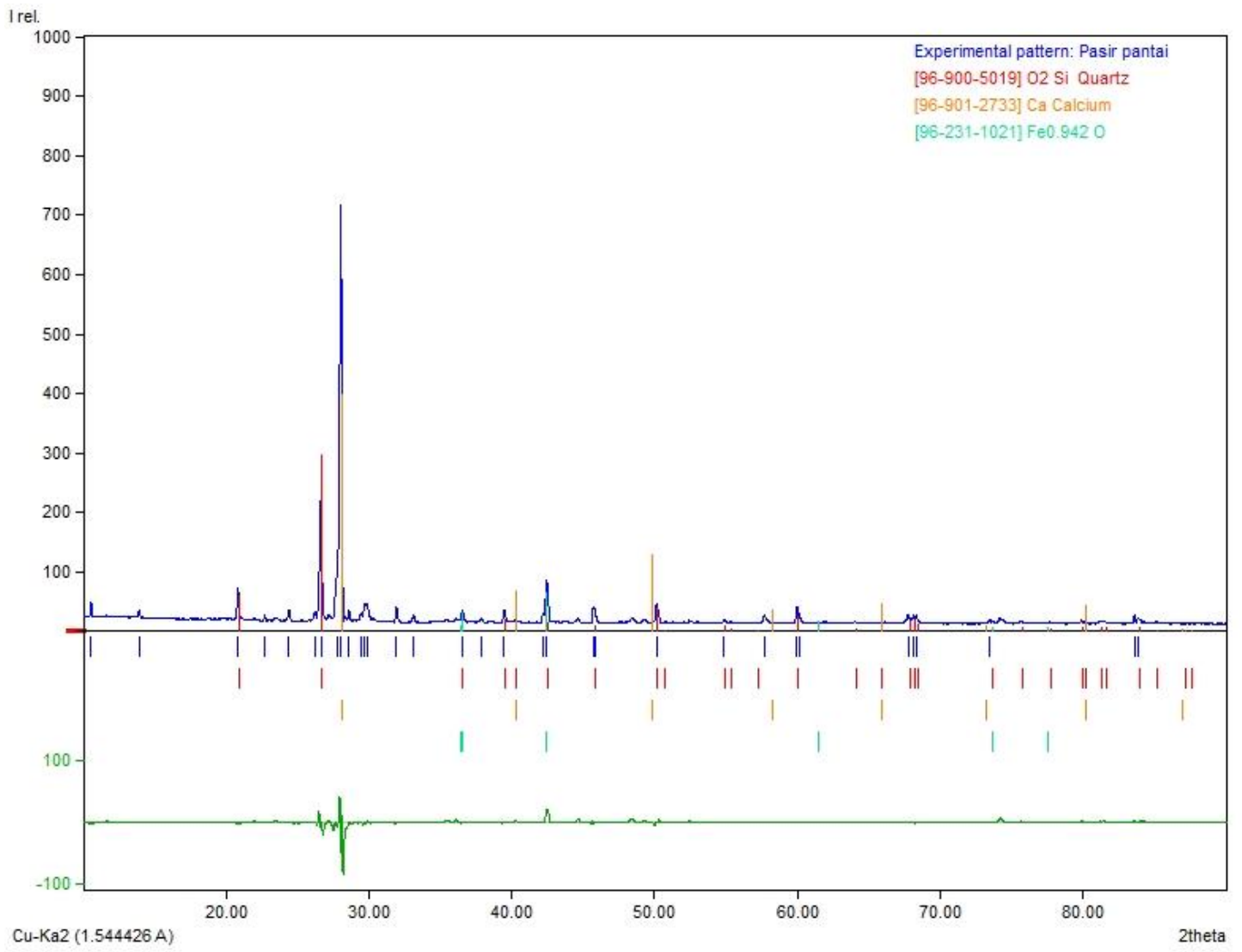

Gambar 2. Hasil Analisis Kuantitatif Data XRD Sampel Pasir Pantai Bajul Mati

Gambar 2 menunjukkan bahwa dua fase yang mendominasi pada sampel pasir pantai Bajul Mati adalah fase quartz $\left(\mathrm{SiO}_{2}\right)$ dan calcium. Hasil XRD ini diperkuat dengan kesesuaian hasil uji XRF dengan senyawa oksida terbesar yang terkandung dalam sampel pasir Bajul Mati adalah silika $\left(\mathrm{SiO}_{2}\right)$. Hasil tersebut juga memperkuat pasir pantai Bajul Mati dapat dimanfaatkan sebagai bahan dasar pembuatan nanosilika dengan kandungan utama quartz yakni $\mathrm{SiO}_{2}$ dan silika juga terdapat dalam persenyawaan mineral yang terdapat pada pasir pantai [11]. Terdapatnya mineral besi (Fe) juga menandakan bahwa pasir pantai Bajul Mati dapat dipergunakan dalam pembuatan material magnetik [12].

\section{Ucapan terima kasih}

Terima kasih diucapkan kepada Kementerian Riset, Teknologi, dan Pendidikan Tinggi yang telah mendanai seluruh penelitian ini melalui Hibah PKM Penelitian pendanaan tahun 2019 dan kepada bidang Kemahasiswaan Universitas Negeri Malang yang telah memfasilitasi terselenggaranya hibah PKM-PE pendanaan tahun 2019.

\section{Kesimpulan}

Berdasarkan hasil analisis unsur dan oksida logamnya serta mineral yang terkandung pada pasir pantai Bajul Mati, maka ditarik kesimpulan bahwa pasir pantai Bajul Mati berpotensi sebagai bahan dasar pembuatan nanosilika. Hasil analisis XRF menunjukkan kandungan $\mathrm{SiO}_{2}$ sebesar $46,7 \%$ dan hasil analisis XRD menunjukkan mineral silika berfase quartz $\left(\mathrm{SiO}_{2}\right)$.

\section{Daftar Pustaka}

1. BPS, B.P.S. Statistik Sumber Daya Laut dan Pesisir; Badan Pusat Statistika Indonesia: Jakarta, 2018; ISBN 2086-2806.

2. Wibowo, E.A.P.; Arzanto, A.W.; Maulana, K.D.; Rizkita, A.D. Preparasi dan Karakterisasi Nanosilika dari Jerami Padi. Jurnal Ilmiah Sains 2018, 18, 35-40, doi:https://doi.org/10.35799/jis.18.1.2018.1 9089.

3. Jalil, Zulkarnain.; Rahwanto, Adi.; Sofyan, 
Hizir.; Usman, Mustafa.; Handoko, E. The use of Silica from beach sand as catalyst in Magnesium based hydrides for Hydrogen storage materials. IOP Conf. Series: Earth and Environmental Science 2018, 105.

4. BPS, B.P.S.K.M. Statistik Daerah Kabupaten Malang 2017; Badan Pusat Statistik Kabupaten Malang: Malang, 2017;

5. Jolo, A.; Gautama, R.S. Pengelolaan dan Pemanfaatan Sumber Daya Mineral Berwawasan Lingkungan (Studi Kasus Kabupaten Halmahera Utara). Techno: Jurnal Penelitian 2018, 7, 128-142, doi:http://dx.doi.org/10.33387/tk.v7i01.35 5.

6. Ardelean, I.L.; Bogdan, L.; Stoencea, N.; Ficai, D.; Ficai, A.; Trusca, R.; Vasile, B.S.; Nechifor, G.; Andronescu, E. Development of Stabilized Magnetite Nanoparticles for Medical Applications. Journal of Nanomaterials 2017, 2017, doi:https://doi.org/10.1155/2017/6514659.

7. Sugimoto, S. Current status and recent topics of rare-earth permanent magnets. Journal of Physics D: Applied Physics 2011, 44, 64001, doi:10.1088/00223727/44/6/064001.

8. Handoko, A.D.; Sanjaya, E. Characteristics and genesis of Rare Earth Element $(\{$ REE $\})$ in western Indonesia. IOP Conference Series: Earth and Environmental Science 2018, 118, doi:10.1088/1755-1315/118/1/012077.

9. Ukhtiyani, Indah.; Darwis, Darmawati.; Iqbal Purifikasi dan Karakterisasi Silika (SiO2) Berbasis Pasir Kuarsa dari Desa Pasir Putih Kecamatan Pamona Selatan Kabupaten Poso. Natural Science: Journal of Science and Technology 2017, 6, 270-275.

10. Shofiyani, A.; Chitra, F.; Rahmalia, W.; Rudiyansyah, R.; Alimuddin, A.H. Synthesis of Nanosilica from Padas Stone to Reduce The Total Organic Carbon of Palm Oil Waste. Jurnal Ilmu Dasar 2019, 20, 39-46, doi:10.19184/jid.v20i1.8679.

11. Rozi, T.Y.; Astuti Pengaruh Temperatur Kalsinasi pada Sintesis Nanopartikel Silika Pantai Purus Kota Padang. Jurnal FIsika Unand 2016, 5, 351-356, doi:https://doi.org/10.25077/jfu.5.4.351356.2016.
12. Widianto, E.; Kardiman; Fauji, N. Karakterisasi Pasir Besi Alam Pantai Samudera Baru dan Pemanfaatannya sebagai Filler pada Sistem Penyaring Elektromagnetik. Jurnal Riset Sains dan Teknologi 2018, 2, 15-20, doi:10.30595/jrst.v2i1.2325.

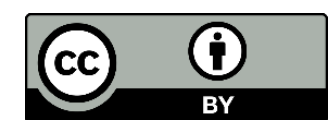

(C) 2020 by the authors. Licensee Fullerene Journal Of Chem. This article is an open access article distributed under the terms and conditions of the Creative Commons Attribution (CC BY) license

(http://creativecommons.org/licenses/by/4.0/). 